\title{
Levantamento dos fitoterápicos comercializados em uma Farmácia do municipio de Cerro Largo, RS, Brasil e informações terapêuticas das principais espécies vegetais ativas
}

\author{
Survey of the herbal medicines marketed in a Pharmacy \\ in the city of Cerro Largo, RS, Brazil, and therapeutic \\ information of the main active plant species
}

Recebido em: 26/04/2019

Aceito em: 30/07/2019

Elisa da SILVA; Leandro Nicolodi FRANCESCATO

Pós-graduação em Prescrição Farmacêutica e Farmácia Clínica, Universidade Regional Integrada do Alto Uruguai e das Missões (URI),

Campus de Santo Angelo. Rua Universidade das Missões, 464,

Bairro Universitário, CEP 98802-470, Santo Angelo, RS, Brasil.

E-mail: leandrofrancescato@yahoo.com.br

ABSTRACT:

This work aimed to perform a survey of the commercial and compounding herbal medicines most commercialized in a local Pharmacy, in the city of Cerro Largo, RS, Brazil and searching for the therapeutic information about the active plant species in the main products. A retrospective survey of products sold in 2016 was carried out. During the mentioned period, 986 units of commercial herbal medicines were dispensed, comprising 57 different products and 144 units of compounding herbal medicines were produced, comprising 8 different products $(1.74 \%$ and $1.5 \%$ of net sales value of commercial and compounding products, respectively). Eighteen plant species were more present in the industrialized products and five species were more present in the compounding production, representing $91.3 \%$ and $89.6 \%$ of the total units, respectively. The commercialization of herbal medicines was small and the majority of the commercialized products were focused in a few species. Thus, the therapeutic information of the 21 main plant species was compiled, and verified the side-effects, contraindications and drug interactions for most of them. After this survey we considered this informations highly important to the pharmaceutical assistance, regarding the correct and appropriate use of these herbal medicines

Keywords: Phytotherapy; Phytotherapeutic Drugs; Pharmacy; Pharmaceutical Services.

\section{RESUMO}

O objetivo deste trabalho foi realizar o levantamento dos fitoterápicos industrializados e magistrais mais comercializados em uma Farmácia, do município de Cerro Largo, RS, e buscar as informações terapêuticas das espécies vegetais ativas presentes nos principais produtos. Para isto, foi realizado o levantamento retrospectivo de vendas dos produtos fitoterápicos industrializados e magistrais, comercializados no ano de 2016. Durante o período avaliado foram dispensadas 986 unidades de fitoterápicos industrializados, compreendendo 57 tipos de produtos e produzidas 144 unidades de fitoterápicos magistrais, compreendendo 8 
tipos de produtos $(1,74 \%$ e $1,5 \%$ do valor líquido de vendas de medicamentos industrializados e produtos manipulados, respectivamente). Dezoito espécies vegetais estiveram mais presentes nos produtos industrializados comercializados, representando $91,3 \%$ do total de unidades comercializadas; 5 espécies estiveram mais presentes na produção magistral, representando $89,6 \%$ do total de unidades manipuladas. A comercialização de fitoterápicos era pequena e a maior parte dos produtos comercializados concentravam-se em poucas espécies vegetais. Assim, neste trabalho, foram compiladas as informações terapêuticas das 21 espécies vegetais ativas principais. Muitas delas apresentam importantes efeitos adversos, contraindicações e interações, sendo estas informações de suma importância para a orientação do farmacêutico aos usuários quanto ao uso correto e adequado dos produtos fitoterápicos.

Palavras-chave: fitoterapia; medicamentos fitoterápicos; farmácia; assistência farmacêutica.

\section{INTRODUÇÃO}

Fitoterápicos são produtos alopáticos derivados de plantas, usados com propósitos medicinais e para promoção da saúde. Segundo a Resolução da Diretoria Colegiada (RDC) $n^{\circ}$ 26/2014, da Agência Nacional de Vigilância sanitaria (Anvisa). são considerados Medicamentos Fitoterápicos "os obtidos com emprego exclusivo de matérias-primas ativas vegetais, cuja segurança e eficácia sejam baseadas em evidências clínicas e que sejam caracterizados pela constância de sua qualidade". Os Produtos Tradicionais Fitoterápicos, diferem quanto à segurança e efetividade, pois são "baseadas em dados de uso seguro e efetivo, publicados na literatura técnico-científica" (1).

O uso de fitoterápicos aumentou mundialmente nos últimos anos, assim como outras práticas complementares e alternativas de tratamento. As projeções do Instituto Brasileiro de Plantas Medicinais (IBPM) mostram que o mercado de medicamentos fitoterápicos movimenta até 500 milhões de dólares por ano no Brasil. Além disso, o mercado mundial de fitoterápicos cresce de $6 \%$ a $7 \%$ ao ano, enquanto o mercado farmacêutico tradicional apresenta um crescimento anual de apenas $3 \%$ a $4 \%(2,3)$.

O conceito de "natural" em muito contribui para o aumento do uso de fitoterápicos nos últimos tempos. Popularmente, este conceito está ligado à ausência de produtos químicos e certa inocuidade, sendo que produtos naturais passaram a ser sinônimo de produtos saudáveis, seguros e benéficos. Mas, apesar de naturais, muitos produtos fitoterápicos podem causar danos à saúde, devido às interações medicamentosas, efeitos adversos e até toxicidade, quando empregados de maneira inadequada, sendo muito importante a atuação do profissional farmacêutico na dispensação e promoção do uso racional de fitoterápi$\cos (4,5)$.

Para que ocorra o uso racional de fitoterápicos, mesmo no contexto da automedicação, é imprescindível que informações a respeito destes produtos cheguem até o consumidor/usuário, de forma facilmente compreensível, com dados sobre segurança e eficácia, descrição do modo de usar e situações nas quais o acompanhamento médico é necessário. $\mathrm{O}$ entendimento do uso racional de medicamentos também compreende a prescrição apropriada, a dispensação em condições adequadas e o consumo nas doses indicadas, nos intervalos definidos e no período de tempo indicado $(6,7)$.

A legislação vigente permite a dispensação de medicamentos fitoterápicos, apenas em farmácias, drogarias ou dispensários de medicamentos (8), onde o farmacêutico é a mais importante e acessível fonte de informação. De acordo com a Resolução $n^{\circ} 585$ do Conselho Federal de Farmácia (CFF), "as atribuições clínicas do farmacêutico visam proporcionar cuidado ao paciente, família e comunidade, de forma a promover o uso racional de medicamentos e aperfeiçoar a farmacoterapia [...] permitindo que o paciente utilize de forma segura os medicamentos de que necessita" (9).

Apesar disto, o conhecimento dos farmacêuticos e outros profissionais de saúde acerca 
da Fitoterapia é limitado, pois essa terapêutica é pouco abordada nas grades curriculares de graduação, e existe certa carência de bibliografias compiladas em língua portuguesa, sendo que as informações mais atuais e relevantes, aparecem em artigos científicos em língua estrangeira e são de difícil acesso à maior parte dos profissionais.

Considerando estes aspectos, este trabalho buscou avaliar quais são os produtos fitoterápicos manipulados e industrializados mais comercializados em uma Farmácia do município de Cerro Largo, RS e compilar as informações terapêuticas das principais espécies vegetais ativas presentes nestes produtos.

\section{MÉTODO}

Este estudo apresenta caráter documental retrospectivo e descritivo. Foi realizado um levantamento dos fitoterápicos industrializados (medicamentos fitoterápicos e produtos tradicionais fitoterápicos) comercializados em uma farmácia do município de Cerro Largo, RS, Brasil, no período de 01 de janeiro a 31 de dezembro de 2016. Para isto, foi acessado o relatório de vendas informatizado de produtos, procurando por aqueles classificados como "fitoterápicos" e após, uma busca manual nas vendas de todos os medicamentos, buscando por fitoterápicos que poderiam estar erroneamente classificados. Também foi realizado um levantamento dos produtos fitoterápicos magistrais (manipulados) comercializados entre 01 de março e 31 de dezembro de 2016, a partir do histórico de produção deste período, o qual se encontrava disponível.

Foram excluídos da amostra os produtos que tenham sido erroneamente cadastrados no sistema como medicamentos fitoterápicos. Também foram excluídos da amostra produtos que, apesar de conterem matéria-prima ativa vegetal, possuem substâncias ativas isoladas na formulação, os suplementos alimentares e também aqueles que são considerados alimentos.

A análise quantitativa foi realizada a partir das unidades comercializadas, sendo considerado como uma unidade o produto em sua embala- gem final, independente da dosagem ou unidades posológicas contidas na mesma. Os resultados obtidos foram organizados e analisados com auxílio do programa Excel $^{\circledR}$ (Microsoft Office, 2010).

Complementarmente, foi realizado um levantamento bibliográfico dos medicamentos fitoterápicos que tiveram maior comercialização, buscando-se informações relevantes do ponto de vista terapêutico. Para isto foram consultadas algumas bases de dados, como PubMed, ScienceDirect, Scielo e Medscape, em busca de artigos científicos, além dos Compêndios da Farmacopeia Brasileira (Disponível em: http://portal.anvisa.gov.br/farmacopeia) e, das monografias da World Health Organization (Disponível em: https://apps.who.int/medicinedocs/en/d/Js2200e/) e European Medicines Agency (Disponível em: https://www.ema.europa.eu/en/medicines), entre outras. Foram consultadas referências em língua inglesa e portuguesa, utilizando como descritores de busca, os nomes científicos das espécies vegetais.

\section{RESULTADOS E DISCUSSÃO}

Durante o ano de 2016 foram comercializadas, no estabelecimento avaliado, 986 unidades de fitoterápicos industrializados, compreendendo 57 tipos de produtos (Tabela 1) e produzidas 144 unidades de fitoterápicos magistrais, compreendendo 8 tipos de produtos (Tabela 2 ).

Ao considerar o valor líquido de vendas e o número de unidades de produtos comercializados, o percentual de venda dos fitoterápicos industrializados foi de apenas $1,74 \%$, e $1,49 \%$, respectivamente, em relação aos medicamentos alopáticos convencionais e suplementos alimentares (dados não apresentados).

Este percentual é próximo ao encontrado por Oliveira (2015), 1,78\%, ao analisar a supressão de vendas de fitoterápicos em três drogarias no Estado de Mato Grosso (10). Nesta ocasião, o autor verificou, por entrevistas, que este baixo valor era, em parte, atribuído à falta de conhecimento por parte dos profissionais farmacêuticos para a sua indicação, pois a maioria dos fitoterápicos eram isentos 
de prescrição médica, e, também, à pouca aceitação pela população, que não confiava plenamente em medicamentos fitoterápicos, ou desconhecia quais eram eles.

Dos medicamentos fitoterápicos magistrais, o percentual do valor líquido de vendas, em relação ao total de vendas de produtos manipulados, foi de, aproximadamente, 1,5\% (dados não apresentados). Este percentual também é inferior ao encontrado por Vieira e cols (2010), que ao avaliarem a comercialização de medicamentos fitoterápicos em duas farmácias magistrais em Dourados, MS, verificaram que a porcentagem de produtos fitoterápicos em relação ao total de medicamentos manipulados foi de $4,1 \%$ (4).

O baixo percentual encontrado no presente trabalho pode ter sido influenciado pelas dificuldades de acesso aos dados do sistema gerencial de manipulação, sendo o valor de venda líquida dos fitoterápicos magistrais comparado ao total de venda de todos os produtos magistrais, incluindo os alimen- tos especiais, produtos de higiene e cosméticos, e não só os medicamentos.

Em relação à via de administração dos fitoterápicos industrializados (Tabela 1), a grande maioria $(89,5 \%, n=51)$, era de utilização por via oral, dos quais, $58,8 \%(\mathrm{n}=30)$ eram formas farmacêuticas sólidas, principalmente comprimidos $(35,3 \%, \mathrm{n}$ $=18)$, e soluções orais $(23,5 \%, n=12)$. A maior parte dos insumos farmacêuticos ativos vegetais empregados eram extratos secos $(54,4 \%, \mathrm{n}=31)$. As formas farmacêuticas sólidas possuem grande aceitação pela população, sendo as mais comumente dispensadas, principalmente cápsulas e comprimidos, em grande parte pelo fato de ser a forma de administração de maior facilidade e comodidade ao paciente (11).

Quase a metade dos produtos fitoterápicos $(42,1 \%, \mathrm{n}=24)$ não se encontravam cadastrados no sistema de vendas como "fitoterápico", e sim como medicamentos de referência ou similares (Tabela 1). 


\section{lutarma}

需

焉

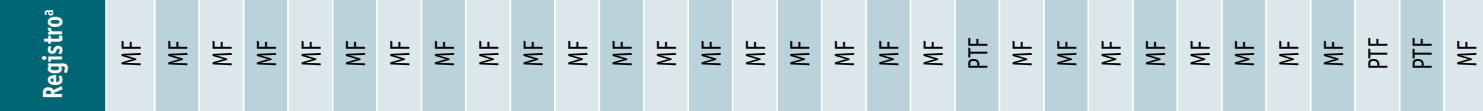

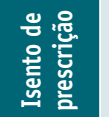

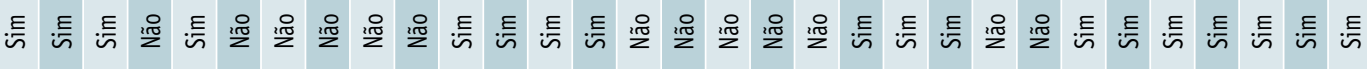

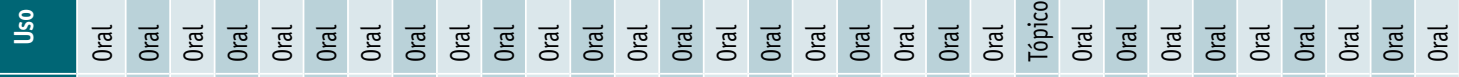

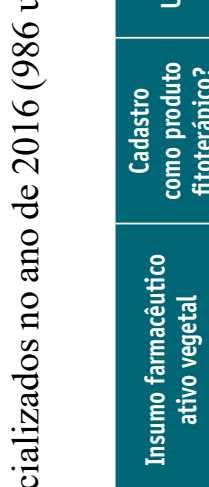

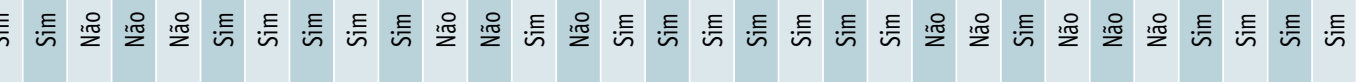

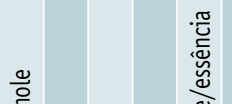

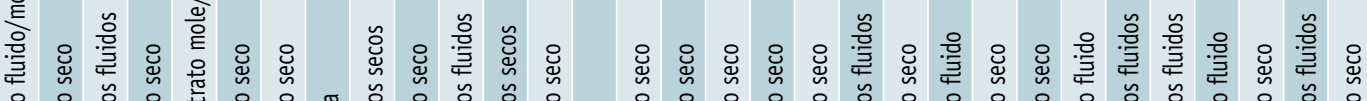

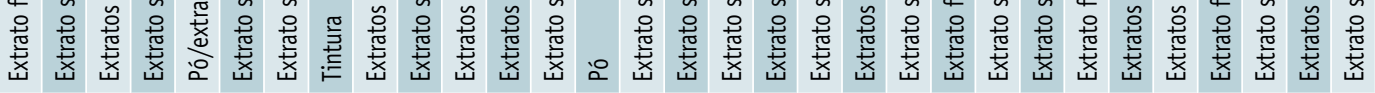

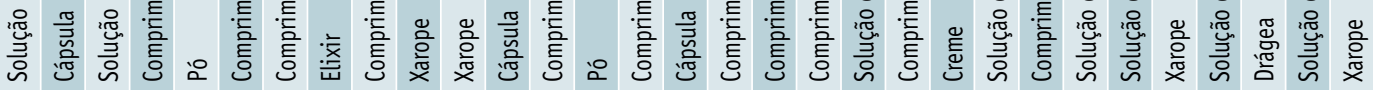

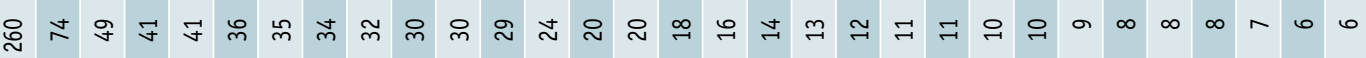
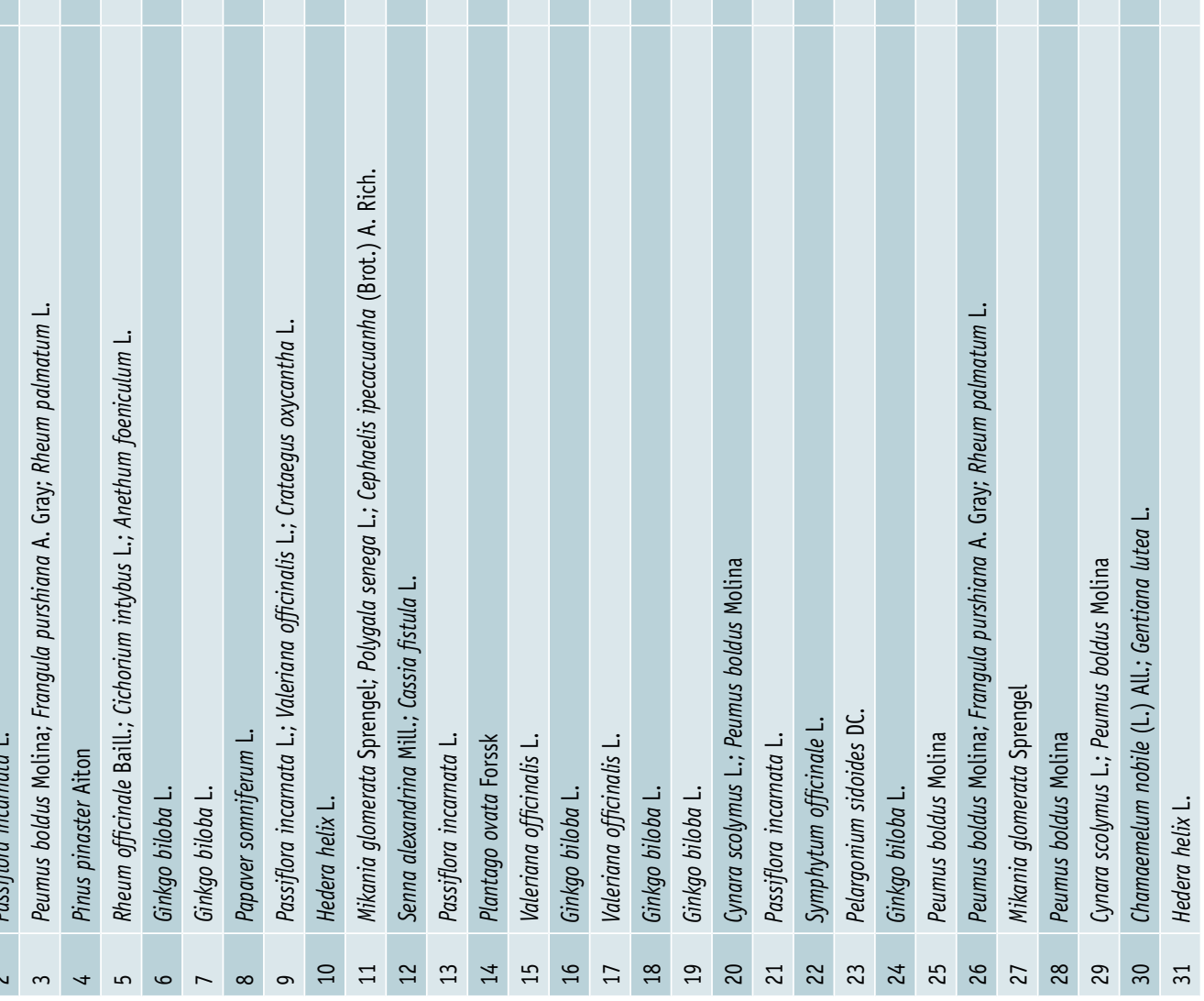


\section{luftarma}

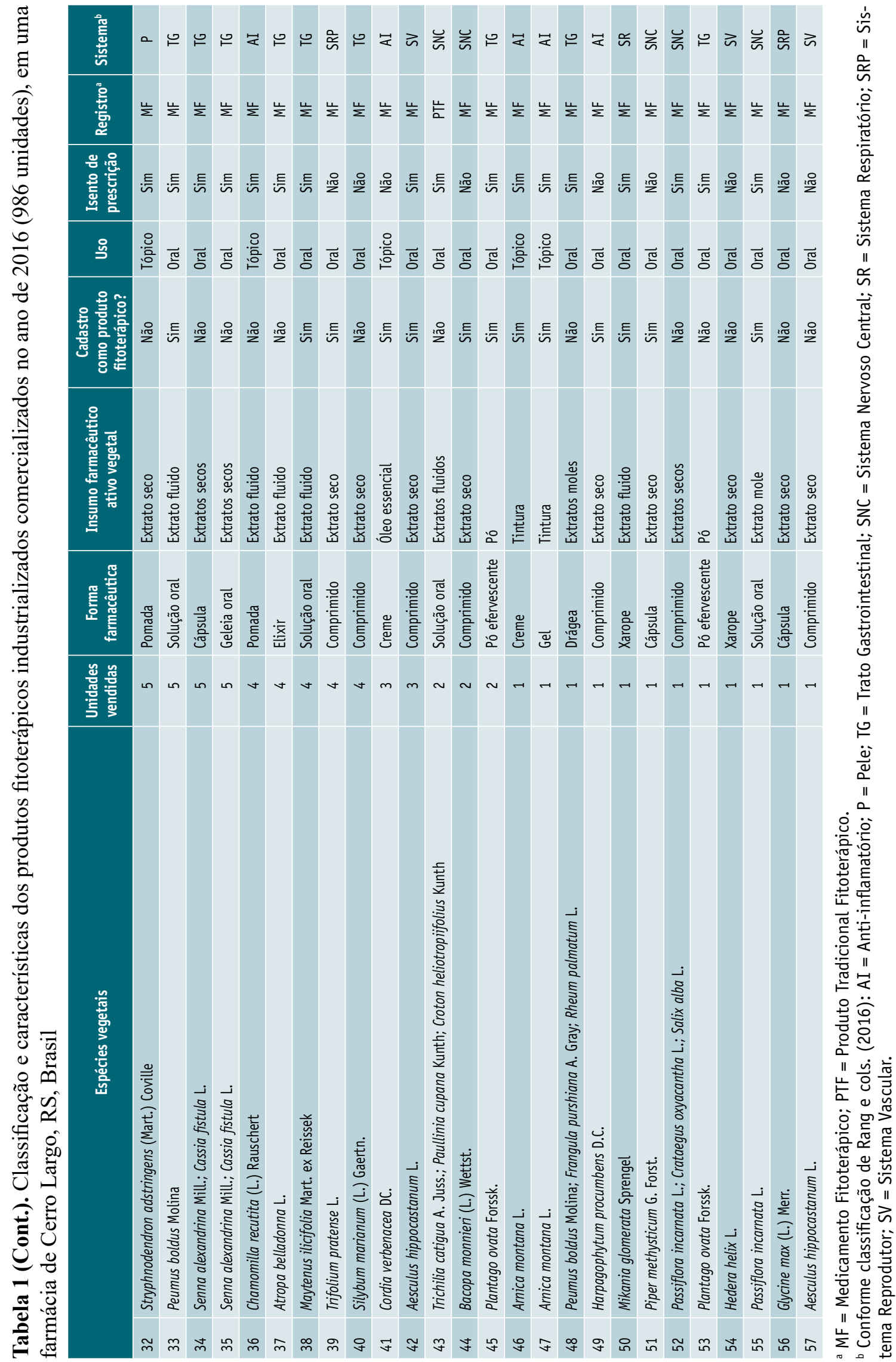


Tabela 2. Produtos fitoterápicos magistrais manipulados no período de março a dezembro de 2016 (144 unidades), em uma farmácia de Cerro Largo, RS, Brasil

\begin{tabular}{|c|c|c|c|c|c|c|}
\hline Espécie vegetal ativa & Nome popular & $\begin{array}{c}\text { Forma } \\
\text { Farmacêutica }\end{array}$ & $\begin{array}{c}\text { Insumo } \\
\text { Farmacêutico } \\
\text { Ativo }\end{array}$ & Uso & Sistema ${ }^{a}$ & $\begin{array}{l}\text { Unidades } \\
\text { produzidas }{ }^{b}\end{array}$ \\
\hline Aesculus hippocastanum L. & Castanha-da-Índia & Cápsula & Pó & Oral & SV & 50 \\
\hline Ginkgo biloba L. & Ginkgo & Cápsula & Extrato seco & Oral & SV & 38 \\
\hline Valeriana officinalis L. & Valeriana & Cápsula & Pó & Oral & SNC & 21 \\
\hline Cynara scolymus L. & Alcachofra & Cápsula & Extrato seco & Oral & TG & 10 \\
\hline Matricaria chamomilla L. & Camomila & Gel & Extrato glicólico & Tópico & AI & 10 \\
\hline Pinus pinaster Aiton & Pinheiro & Cápsula & Extrato seco & Oral & SV & 7 \\
\hline Uncaria tomentosa Willd. & Unha-de-gato & Cápsula & Pó & Oral & AI & 6 \\
\hline Harpagophytum procumbens D.C. & Garra-do-diabo & Cápsula & Pó & Oral & AI & 2 \\
\hline
\end{tabular}

a Conforme classificação de Rang e cols. (2016): AI =Anti-inflamatório; TG =Trato Gastrointestinal; SNC =Sistema Nervoso Central; SV =Sistema Vascular.

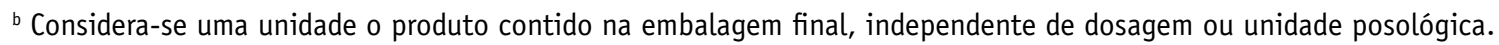

Além disso, muitos produtos não considerados fitoterápicos (por conterem substâncias ativas isoladas na fórmula), e a grande maioria dos suplementos alimentares, como por exemplo, guaraná em pó e os óleos de chia e linhaça, estavam erroneamente cadastrados como fitoterápicos no sistema da Farmácia em questão. Estas divergências podem ser, principalmente, atribuídas a questões de precificação e sistemas de descontos estabelecidos pelo fornecedor e/ou pela farmácia para cada tipo de produto, fato este também observado em outras drogarias da região. Entretanto, algumas vezes, isto também pode ocorrer pelo desconhecimento do que de fato é um medicamento fitoterápico, sendo usualmente considerado fitoterápico tudo aquilo que contém em sua composição algum produto de origem vegetal, e as vezes, até o própolis, um produto de origem animal.

Dos fitoterápicos avaliados (Tabela 1), 93\% (n = 53) estavam registrados na Anvisa como Medicamento Fitoterápico, conforme apresentado nas embalagens dos produtos, enquanto apenas $7 \%$ (n =4) estavam registrados como Produto Tradicional Fitoterápico $(1,12)$.

Além dos Produtos Tradicionais Fitoterápicos, a maior parte dos Medicamentos Fitoterápicos apresentavam-se como produtos isentos de prescrição, correspondendo a $61,4 \%(n=35)$ dos produtos analisados. Este é um dado bastante interessante e favorável, visto que o farmacêutico está apto a prescrever medicamentos isentos de prescrição mé- dica (MIP), no contexto da Atenção Farmacêutica (AF) (13). A AF é uma das formas do farmacêutico exercer seu papel como profissional de saúde na comunidade, podendo solucionar problemas de saúde autolimitados, revisar a farmacoterapia e realizar o acompanhamento farmacoterapêutico. Neste contexto, a prescrição de MIP fitoterápicos é um importante nicho a ser explorado, visto que contemplam opções terapêuticas que muitas vezes os MIP's alopáticos convencionais não abrangem, como os medicamentos atuantes no Sistema Nervoso Central (SNC) e no Sistema Digestivo, por exemplo.

Quanto aos sistemas corporais no qual os fitoterápicos podem atuar, a maioria era indicada no tratamento de problemas do Trato Gastrointestinal $(36,8 \%, n=21)$, seguido do SNC $(19,3 \%, n=11)$, Sistema Vascular $(17,5 \%, \mathrm{n}=10)$ e Sistema Respiratório $(10,5 \%, \mathrm{n}=6)(14)$.

Ao avaliar as principais espécies vegetais ativas presentes nos produtos fitoterápicos industrializados simples ou compostos (Tabela 3), foi observado que apenas 18 espécies vegetais ativas estavam presentes nos produtos que tiveram mais de 32 unidades comercializadas e, que estas poucas espécies estavam presentes em 91,3\% $(n=900)$ do total das unidades industrializadas comercializadas $(\mathrm{n}=986)$ no período avaliado.

As espécies vegetais ativas presentes nos produtos mais comercializados foram similares ao encontrado em outras pesquisas. Oliveira (2015) 
encontrou Hedera helix L., Valeriana officinalis L. e Passiflora incarnata L., como as espécies vegetais ativas dos medicamentos fitoterápicos mais comercializados em três drogarias no município de Colider, MT (10). Bello e cols (2002) encontraram Passiflora incarnata L., Peumus boldus Molina e Senna alexandrina Mill. entre os fitoterápicos mais comercializados em 13 drogarias do município de Porto Alegre, RS (15). Ginkgo biloba L., Cynara scolymus L. e Aesculus hippocastanum $\mathrm{L}$. foram os fitoterápicos mais solicitados em farmácias e drogarias em Porto Alegre, RS, conforme citado por farmacêuticos no estudo de Heckler e cols (2005) (6).
Com esta informação, é possível perceber que o farmacêutico precisa ter conhecimento e estar atualizado sobre uma pequena parcela de espécies vegetais ativas para poder orientar de maneira adequada a grande maioria das dispensações de medicamentos fitoterápicos. Além disso, das 18 espécies mais comercializadas na farmácia avaliada, 13 delas $(72,2 \%)$ estavam presentes em MIP, sendo passíveis de prescrição farmacêutica, o que pode enriquecer o arsenal de opções terapêuticas no contexto da AF. Além disso, muitas destas espécies já estão disponíveis em compêndios em língua portuguesa, como o Memento Fitoterápico (16) e Formulário de Fitoterápicos da Farmacopeia Brasileira (17).

Tabela 3. Espécies vegetais ativas presentes em produtos fitoterápicos industrializados com maior comercialização no ano de 2016 e sua variação trimestral de venda em uma farmácia de Cerro Largo, RS, Brasil

\begin{tabular}{|c|c|c|c|c|c|c|c|}
\hline \multirow{3}{*}{\multicolumn{2}{|c|}{ Espécie vegetal ativa }} & \multirow{3}{*}{$\begin{array}{l}\text { Produtos } \\
\text { comerciais onde } \\
\text { estão presentes }\end{array}$} & \multicolumn{5}{|c|}{ Unidades comercializadas } \\
\hline & & & \multicolumn{4}{|c|}{ Trimestre/2016 } & \multirow{2}{*}{ Total } \\
\hline & & & $1^{\circ}$ & $2^{\circ}$ & $3^{\circ}$ & $4^{\circ}$ & \\
\hline 1 & Gentiana lutea L. & 2 & 72 & 66 & 64 & 64 & 266 \\
\hline 2 & Aloe ferox Mill. & 1 & 70 & 65 & 63 & 62 & 260 \\
\hline 3 & Passiflora incarnata L. & 5 & 44 & 27 & 33 & 39 & 143 \\
\hline 4 & Ginkgo biloba L. & 6 & 36 & 31 & 29 & 30 & 126 \\
\hline 5 & Peumus boldus Molina & 5 & 29 & 19 & 23 & 28 & 99 \\
\hline 6 & Valeriana officinalis L. & 3 & 28 & 19 & 13 & 8 & 68 \\
\hline 7 & Frangula purshiana A. Gray & 1 & 15 & 11 & 17 & 15 & 58 \\
\hline 8 & Rheum palmatum L. & 1 & 15 & 11 & 17 & 15 & 58 \\
\hline 9 & Anethum foeniculum L. & 1 & 3 & 22 & 10 & 6 & 41 \\
\hline 10 & Cichorium intybus L. & 1 & 3 & 22 & 10 & 6 & 41 \\
\hline 11 & Pinus pinaster Aiton & 1 & 11 & 13 & 10 & 7 & 41 \\
\hline 12 & Rheum officinale Baill. & 1 & 3 & 22 & 10 & 6 & 41 \\
\hline 13 & Cassia fistula L. & 2 & 11 & 10 & 11 & 7 & 39 \\
\hline 14 & Mikania glomerata Sprengel & 3 & 8 & 13 & 15 & 3 & 39 \\
\hline 15 & Senna alexandrina Mill. & 2 & 11 & 10 & 11 & 7 & 39 \\
\hline 16 & Hedera helix L. & 3 & 1 & 8 & 21 & 7 & 37 \\
\hline 17 & Papaver somniferum $\mathrm{L}$. & 1 & 9 & 11 & 10 & 4 & 34 \\
\hline 18 & Crataegus oxycantha L. & 1 & 19 & 9 & 4 & 0 & 32 \\
\hline
\end{tabular}

Quanto à sazonalidade dos produtos fitoterápicos industrializados de maior comercialização (Tabela 3), houve uma discreta variação nos trimestres. A variação mais significativa ocorreu com Mikania glomerata Sprengel e Hedera helix L., sendo o maior consumo no segundo e terceiro trimestre, o que provavelmente está relacionado ao período mais frio na região. A principal indicação destes produtos é como expectorante e é no inverno que as infecções respiratórias estão mais presentes.

Quanto aos produtos fitoterápicos magistrais (Tabela 2), 5 espécies vegetais mais se destacaram em relação à quantidade comercializada $(\geq 10$ uni- 
dades comercializadas), representando $89,6 \%$ do total de unidades manipuladas no período avaliado, sendo elas, em ordem decrescente: Aesculus hippocastanum L., Ginkgo biloba L., Valeriana officinalis L., Cynara scolymus L. e Matricaria chamomilla L. Estas espécies são indicadas principalmente para problemas no Sistema Vascular, Sistema Nervoso Central (SNC), Trato Gastrintestinal e como anti-inflamatório, seja em produtos industrializados ou manipulados.

Quanto às formas de utilização, houve predominância das fórmulas de utilização oral, sendo a cápsula a forma farmacêutica mais produzida. Tal constatação é autoexplicativa, pois a produção de comprimidos praticamente não ocorre no setor magistral, e poucos são os produtos veiculados nas formas de soluções ou xaropes. No entanto, ao contrário dos produtos industrializados, o insumo vegetal predominante foi a forma pó e não extrato seco. Isto ocorre principalmente pela maior oferta e menor custo de aquisição deste insumo, e também pela tradicionalidade do uso do pó em produtos magistrais.

Duas das principais espécies presentes nos produtos magistrais também foram encontradas entre os produtos fitoterápicos industrializados mais comercializados, Ginkgo biloba L. e Valeriana officinalis L.

Produtos com Ginkgo biloba L. foram os fitoterápicos mais utilizados por idosos em Belo Horizonte, MG (18) e os mais produzidos magistralmente em duas farmácias de Dourados, MS, sendo que em uma delas, Valeriana officinalis apareceu como terceira matéria-prima mais utilizada (4). Melo e cols (2018) encontraram Passiflora incarnata L., Cynara scolymus L. e Rhamnus purshiana DC. entre as 5 plantas medicinais mais dispensadas, principalmente na forma cápsula, em uma farmácia de manipulação de Belém, PA (11). Moraes e cols (2019) encontraram Aesculus hippocastanum L. e Vitis vinifera L. entre os fitoterápicos de maior comercialização em uma farmácia de manipulação de Vitória da Conquista, BA, sendo as formas farmacêuticas sólidas, principalmente cápsulas, as mais comercializadas (19).

\section{Informações terapêuticas das espécies vegetais presentes nos produtos fitoterápicos mais comercializados.}

A seguir são apresentadas informações terapêuticas relevantes para a dispensação e prescrição das 21 espécies vegetais ativas de maior comercialização. Foram consideradas aquelas espécies presentes em maior número nos produtos fitoterápicos industrializados comercializados (18 espécies) e produtos fitoterápicos magistrais mais manipulados (5 espécies), sendo que duas espécies aparecem em ambos grupos de produtos.

Visto que muitos produtos fitoterápicos dispensados em farmácias e drogarias são compostos (apresentam mais de uma espécie vegetal ativa em sua composição) e apresentam diferentes teores de marcadores, detalhes terapêuticos mais específicos devem ser obtidos nas respectivas bulas dos produtos, sendo aqui apresentadas informações gerais e relevantes sobre cada espécie vegetal ativa, isoladamente.

\section{1) Aesculus hippocastanum $\mathrm{L}$. \\ Família: Sapindaceae. \\ Nome popular: Castanha-da-índia. \\ Indicações terapêuticas: tratamento da insuficiência venosa e fragilidade capilar.}

Contraindicações: hipersensibilidade e alergia a qualquer componente do fitoterápico, insuficiência renal e hepática. Esse fitoterápico não deve ser utilizado por mulheres grávidas (risco C) sem orientação médica, assim como por crianças e adolescentes.

Efeitos adversos: em casos isolados podem ocorrer prurido, náuseas e desconforto gástrico. Raramente podem ocorrer irritação da mucosa gástrica e refluxo.

Interações medicamentosas: anticoagulantes orais, pois pode potencializar o efeito anticoagulante. Cerca de $90 \%$ de escina ligam-se às proteínas plasmáticas, podendo interferir com a distribuição de outros fármacos.

Posologia: uso oral: dose diária de 32 a 120 mg de glicosídeos triterpênicos expressos em escina anidra. Uso tópico: gel contendo $2 \%$ de escina (16,20-24). 
2) Aloe ferox Mill.

Família: Asphodelaceae.

Nome popular: Aloé, Babosa.

Indicações terapêuticas: tratamento de constipação intestinal ocasional (uso interno). Promove o alívio da dor, inflamações e cicatrização de feridas e queimaduras (uso externo).

Contraindicações (uso interno): hipersensibilidade e alergia aos componentes do fitoterápico, gravidez, lactação e crianças menores de 12 anos. Desconforto abdominal, apendicite, doença de Crohn, Diabetes mellitus, hemorroidas, obstrução intestinal, doença renal, náuseas, vômito e colite ulcerativa.

Efeitos adversos (uso interno): dor e espasmos abdominais. Uso prolongado pode causar hepatite, distúrbios eletrolíticos, acidose metabólica, má absorção, perda de peso, albuminúria e hematúria, fraqueza e hipotensão ortostática, além da pigmentação melanótica da mucosa colônica.

Interações medicamentosas (uso interno): diminuição da absorção de fármacos orais devido a efeito laxativo; o uso prolongado pode ocasionar hipocalemia, potencializando os efeitos dos glicosídeos cardiotônicos e antiarrítmicos como a quinidina, além do desequilíbrio eletrolítico ser agravado no caso de uso de diuréticos tiazídicos, adrenocorticosteróides e raiz de alcaçuz.

Posologia: uso oral; 10 a $30 \mathrm{mg}$ de derivados hidroxiantracênicos, calculados como aloína, uma vez ao dia, à noite. Não usar por mais de 1 semana $(20,22,25-27)$.

3) Anethum foeniculum L. (sinonímia: Foeniculum vulgare Mill.)

Família: Apiaceae.

Nome popular: Funcho.

Indicações terapêuticas: antiflatulento, antidispéptico e antiespasmódico, e como expectorante, na tosse associada ao frio.

Contraindicações: hipersensibilidade, crianças menores de 4 anos de idade e menores de 18 anos (óleo essencial).

Efeitos adversos: náuseas e vômitos, urticária, erupção cutânea, coceira, aumento leve do fluxo menstrual.
Interações medicamentosas: antibióticos e anti-inflamatórios, indometacina.

Posologia: uso oral: infusão, 1,5 a 2,5 g de frutos de funcho triturados para $250 \mathrm{~mL}$ de água fervente; óleo essencial: $0,2 \mathrm{~mL}$ ao dia em dose única ou dividida. Não utilizar por tempo maior que duas semanas $(20,25,28-30)$.

4) Cassia fistula L.

Família: Fabaceae.

Nome popular: Canafístula.

Indicações terapêuticas: laxante suave (principal indicação). Existem outras atividades biológicas descritas na literatura.

Contraindicações: nenhuma informação encontrada nas referências consultadas, mas considerando a sua composição química (heterosídeos antracênicos), pode apresentar as mesmas contraindicações que o sene (Senna alexandrina Mill.).

Efeitos adversos: diarreia, aumento da salivação, dor de cabeça e dor abdominal.

Interações medicamentosas: nenhuma informação encontrada nas referências consultadas, mas considerando a sua composição química, pode apresentar as mesmas interações que o sene (Senna alexandrina Mill.).

Posologia: uso oral; $0,1 \mathrm{~g} / \mathrm{Kg}$ de peso corporal, ao dia, da polpa da fruta seca (20,31-34).

\section{5) Cichorium intybus L.}

Família: Asteraceae.

Nome popular: Chicória.

Indicações terapêuticas: constipação, diarreia, falta de apetite e dispepsia.

Contraindicações: gravidez e lactação, cálculos biliares.

Efeitos adversos: dermatite de contato e outras alergias.

Interações medicamentosas: nenhuma informação encontrada nas referências consultadas.

Posologia: uso oral; 2 a $4 \mathrm{~g}$ da droga vegetal em infusão ou decocção, uma vez ao dia (20,35-37).

6) Crataegus oxyacantha L.

Família: Rosaceae.

Nome popular: Cratego. 
Indicações terapêuticas: indicado para o tratamento de sintomas cardíacos de origem nervosa temporários, como palpitações e taquicardia devido à ansiedade moderada, para alívio de sintomas suaves de stress mental e para ajudar quadros de insônia.

Contraindicações: gravidez e lactação. Contraindicada a automedicação.

Efeitos adversos: tonturas, vertigens, palpitações, dispneia, cefaleia e desconforto gástrico.

Interações medicamentosas: fármacos anti-hipertensivos, anti-hipotensivos e inotrópicos.

Posologia: uso oral; 240 a $900 \mathrm{mg}$ do extrato seco ao dia. Folha com flor - extrato padronizado em 3,5 a 19,8 mg de flavonoides e 30 a 168,7 mg de procianidinas diariamente, dividido em 2 a 3 doses $(20,22,38)$.

7) Cynara scolymus L.

Familia: Asteraceae.

Nomenclatura popular: Alcachofra.

Indicações terapêuticas: Colagogo e colerético. Tratamento dos sintomas de dispepsia funcional e de hipercolesterolemia leve a moderada.

Contraindicações: hipersensibilidade e alergia a qualquer um dos componentes da planta, obstrução do ducto biliar, evitar durante gravidez e lactação.

Efeitos adversos: em pessoas sensíveis aos componentes da planta, pode ocorrer efeito laxante e dermatite alérgica de contato.

Interações medicamentosas: pode reduzir a eficácia de anticoagulantes cumarínicos e do ácido acetilsalicílico e, reduzir as concentrações sanguíneas de fármacos metabolizados pelas enzimas CIP 3A4, 2B6 e 2D6, sendo que C. scolymus é indutora destas enzimas.

Posologia: uso oral; dose média diária de $6 \mathrm{~g}$ de droga vegetal; 0,5 a $2 \mathrm{~g}$ de extrato seco ao dia, em doses divididas; dose diária de 24 a $48 \mathrm{mg}$ de derivados de ácido cafeoilquínico expressos em ácido clorogênico $(16,17,20-22,25,39,40)$.

8) Frangula purshiana (DC.) A. Gray (sinonímia: Rhamnus purshiana DC.)

Familia: Rhamnaceae.

Nome popular: Cáscara-sagrada.
Indicações terapêuticas: como laxante suave/ moderado na constipação intestinal ocasional.

Contraindicações: hipersensibilidade e alergia aos componentes do fitoterápico, gravidez, lactação e crianças menores de 10 anos. Obstrução intestinal e estenose, atonia, doenças inflamatórias do cólon, apendicite, desidratação grave e depleção de eletrólitos ou constipação intestinal crônica e quaisquer sintomas de distúrbios abdominais não diagnosticados. Não deve ser usada por períodos longos - o uso por mais de 2 semanas requer supervisão médica.

Efeitos adversos: câimbras e desconforto do trato gastrointestinal em doses únicas. Utilização a longo prazo pode ocasionar espasmos abdominais, cólicas e dor, e levar ao desequilíbrio eletrolítico, acidose metabólica, má absorção de nutrientes, perda de peso, albuminúria e hematúria (semelhantes aos relatados para Senna alexandrina Mill.).

Interações medicamentosas: redução da absorção de fármacos administrados oralmente, potencialização dos efeitos dos glicosídeos cardiotônicos e fármacos antiarrítmicos e acentuação da hipocalemia causada por fármacos como diuréticos tiazídicos, adrenocorticosteroides e raiz de alcaçuz.

Posologia: uso oral; droga vegetal, de 0,3 a 1 g; extrato seco, de 57 a $108 \mathrm{mg}$ e; extrato fluido, de 2 a $5 \mathrm{~mL}$ em doses únicas diárias. As preparações devem ser padronizadas para conter 20-30 mg de derivados hidroxiantracênicos, calculados como cascarosídeo A $(16,17,20-22,41)$.

\section{9) Gentiana lutea L.}

Familia: Gentianaceae.

Nome popular: Genciana.

Indicações terapêuticas: distúrbios gastrointestinais, como dispepsia, perda do apetite, flatulência, além de possuir propriedades colagogas, coleréticas e sialagogas.

Contraindicações: hipertensão arterial, hiperacidez e úlceras gástricas ou duodenais; evitar durante a gravidez e lactação.

Efeitos adversos: os extratos de genciana são considerados atóxicos e, em geral, são bem tolerados. Raramente pode ocorrer dores de cabeça. Pode afetar o ciclo menstrual. 
Interações medicamentosas: nenhuma informação encontrada nas referências consultadas.

Posologia: uso oral: infusão, 1-2 g, 3-4 vezes ao dia; $240 \mathrm{mg}$ de extrato seco, 2-3 vezes ao dia; 1 $\mathrm{mL}$ de tintura, $1-3$ vezes ao dia $(20,22,42,43)$.

10) Ginkgo biloba L.

Familia: Ginkgoaceae.

Nome popular: Ginkgo.

Indicações terapêuticas: insuficiência vascular cerebral, distúrbios cognitivos, demência, tonturas, vertigem e zumbidos (tinidos) e claudicação intermitente de origem vascular, degeneração macular, perda de memória, vasodilatador.

Contraindicações: hipersensibilidade e alergia a qualquer um dos componentes da planta, gravidez e lactação, e menores de 12 anos. Pacientes com coagulopatias ou em uso de anticoagulantes e antiagregantes plaquetários devem ser monitorados ou evitar o uso. Evitar a automedicação.

Efeitos adversos: podem ocorrer distúrbios gastrointestinais e diarreia, cefaleia, reações alérgicas cutâneas, náuseas, enjoos, palpitações, hemorragias (alterações plaquetárias) e hipotensão.

Interações medicamentosas: anticoagulantes, antiplaquetários e anti-inflamatórios não esteroidais (AINE's). Pode diminuir a efetividade dos anticonvulsivantes e a biodisponibilidade do omeprazol e alterar os efeitos da insulina, além de mudanças no estado mental quando associado à buspirona ou ao Hypericum perforatum. Pode potencializar o efeito dos inibidores da monoaminaoxidase (IMAO) e pode aumentar o risco dos efeitos colaterais da nifedipina. A associação com trazodona pode ocasionar sedação excessiva e aumentar os riscos de eventos adversos da risperidona. A associação com papaverina pode acarretar potencialização de efeitos terapêuticos e adversos. Pode afetar a atividade de certas enzimas do citocromo P450 (CIP).

Posologia: uso oral; 120 a $240 \mathrm{mg}$ de extrato seco ao dia, divididos em 2 ou 3 doses ou, $0,5 \mathrm{~mL}$ do extrato fluido, 3 vezes ao dia; dose diária de 26,4 a $64,8 \mathrm{mg}$ de ginkgoflavonoides e 6 a $16,8 \mathrm{mg}$ de terpenolactonas $(16,20-22,25,44)$.
11) Hedera helix L.

Família: Araliaceae.

Nome popular: Hera-sempre-verde.

Indicações terapêuticas: mucolítico e expectorante em caso de tosse produtiva.

Contraindicações: hipersensibilidade ou alergia aos componentes do fitoterápico, crianças menores de 2 anos de idade.

Efeitos adversos: raramente pode ocorrer desconforto abdominal, náusea e vômitos; e reações alérgicas como urticária e rash cutâneo.

Interações medicamentosas: nenhuma informação encontrada nas referências consultadas.

Posologia: uso oral; extrato seco, crianças entre 2 e 5 anos: 24 a $36 \mathrm{mg}$ ao dia; crianças entre 6 e 11 anos: 33 a $70 \mathrm{mg}$ ao dia, em doses divididas; adolescentes, adultos e idosos: 45 a $105 \mathrm{mg}$ ao dia, em doses divididas $(20,45,46)$.

12) Matricaria chamomilla L. (sinonímia: Matricaria recutita $\mathrm{L}$.)

Família: Asteraceae.

Nome popular: Camomila, Matricária, Maçanilha.

Indicações terapêuticas: uso oral: antiespasmódico intestinal, dispepsias funcionais; uso tópico: anti-inflamatório.

Contraindicações: hipersensibilidade e alergia aos componentes da planta; evitar o uso excessivo durante a gravidez e lactação; o uso não é recomendado em bebês em dentição.

Efeitos adversos: vômitos, reações alérgicas e dermatite de contato em indivíduos sensíveis; pode afetar o ciclo menstrual.

Interações medicamentosas: varfarina, estatinas e contraceptivos orais.

Posologia: uso oral: crianças maiores de 3 anos: 1 a $4 \mathrm{~mL}$ do extrato fluido, 3 vezes ao dia; acima de 12 anos: $150 \mathrm{~mL}$ do infuso (1,5 a $4 \mathrm{~g}$ de inflorescências secas), 5 a 10 minutos após o preparo, de 3 a 4 vezes ao dia, entre as refeições; dose diária de 4 a 24 mg de apigenina-7-glicosídeo. Uso tópico: gargarejo e/ou bochechos com $100 \mathrm{~mL}$ do infuso ( 6 a $9 \mathrm{~g}$ de inflorescências secas), 5 a 10 minutos após o preparo, 3 vezes ao dia; pomada ou 
gel contendo 3 a $10 \%$ de extrato, contendo 0,005 a $0,05 \mathrm{mg}$ de apigenina-7-glicosídeo por $100 \mathrm{~g}$ ou $100 \mathrm{~mL}$ e 0,004 a $0,07 \mathrm{mg}$ de derivados bisabolônicos calculados como levomenol por $100 \mathrm{~g}$ ou 100 $\mathrm{mL}$. Utilizar tintura apenas topicamente $(16,17,20-$ $22,47,48)$.

\section{3) Mikania glomerata Sprengel}

Família: Asteraceae.

Nome popular: Guaco.

Indicações terapêuticas: expectorante e broncodilatador.

Contraindicações: pacientes que fazem uso de substâncias anticoagulantes. Pode apresentar toxicidade no uso prolongado para pacientes com problemas hepáticos. Evitar o uso durante a gravidez e lactação pela falta de estudos. Cuidado em pacientes com quadros respiratórios crônicos não diagnosticados, devendo-se afastar a hipótese de tuberculose e câncer. Evitar o uso em crianças com idade inferior a 1 ano.

Efeitos adversos: a utilização pode interferir na coagulação sanguínea. Doses acima das recomendadas podem provocar aumento da frequência dos batimentos cardíacos, vômitos e diarreia, que desaparecem com a descontinuação da terapia.

Interações medicamentosas: não utilizar em caso de tratamento com anticoagulantes e lapachol (presente no ipê-roxo). Potencialmente, pode interagir com AINE e com medicamentos utilizados por pacientes com HIV.

Posologia: uso oral: $3 \mathrm{~g}$ da droga vegetal (folhas secas) como infusão, 2 vezes ao dia. Dose diária de 0,5 a $5 \mathrm{mg}$ de cumarina, a qual pode ser dividida em 3 tomadas $(17,20,21,49)$.

\section{4) Papaver somniferum $\mathrm{L}$.}

Família: Papaveraceae.

Nome popular: Papoula, Ópio.

Indicações terapêuticas: antiespasmódico, contra gases, dores estomacais e dores intestinais.

Contraindicações: não deve ser utilizado em pessoas com diarreia aguda. Contraindicado para gestantes, lactantes e crianças menores de 12 anos.

Efeitos adversos: pode causar dependência, sedação, letargia e contrações abdominais. Somen- te observado em doses acima das recomendadas: constipação intestinal, dor de cabeça, sonolência e flatulência.

Interações medicamentosas: as substâncias antidepressivas tais como os IMAO e antidepressivos tricíclicos, as anfetaminas e fenotiazina, podem aumentar os efeitos depressores.

Posologia: uso oral; 0,1 mL de tintura (equivalente a $1 \mathrm{mg}$ de morfina), 3 vezes ao dia. Dose máxima de $0,4 \mathrm{~mL}$ de tintura (equivalente a $4 \mathrm{mg}$ de morfina), dividida em, no mínimo, 4 tomadas $(20,25,50)$.

\section{5) Passiflora incarnata $\mathrm{L}$.}

Família: Passifloraceae.

Nome popular: Maracujá.

Indicações terapêuticas: ansiolítico, sedativo leve e hipnótico.

Contraindicações: tratamento com sedativos e depressores do sistema nervoso. Evitar o uso durante a gravidez e lactação pela falta de estudos. Evitar o uso de dosagens maiores que as recomendadas e/ou por longos períodos. Efeitos adversos: confusão, tontura, sonolência, hepatotoxicidade, náusea e vômito, vasculite, taquicardia ventricular.

Interações medicamentosas: potencialização dos efeitos sedativos do pentobarbital e hexobarbital, da ação anticoagulante da varfarina e dos IMAO.

Posologia: uso oral; 0,5 a $2 \mathrm{~g}$ da droga vegetal, 0,5 a $1 \mathrm{~mL}$ do extrato fluido ou 0,5 a $2 \mathrm{~mL}$ da tintura, de 3 a 5 vezes ao dia para adultos e 3 vezes ao dia para adolescentes. Padronização de uso: 30 a $120 \mathrm{mg}$ de flavonoides totais expressos em vitexina $(16,17,20-22,25,51)$.

\section{6) Peumus boldus Molina:}

Família: Monimiaceae.

Nome popular: Boldo, boldo-do-chile.

Indicações terapêuticas: antidispéptico, colagogo, colerético e para tratamento dos distúrbios gastrointestinais espásticos moderados.

Contraindicações: hipersensibilidade e alergia à planta, gravidez, lactação e pacientes menores de 18 anos de idade. Casos de afecções severas no fígado, obstrução das vias biliares, cálculos bilia- 
res, infecções ou câncer de ducto biliar e câncer de pâncreas. Não exceder a dosagem recomendada.

Efeitos adversos: em doses acima das recomendadas pode causar irritação nas vias urinárias, vômitos e diarreia.

Interações medicamentosas: não foram encontrados dados sobre as interações medicamentosas com fitoterápicos à base de $P$. boldus .

Posologia: uso oral; 0,1 a $0,3 \mathrm{~mL}$ do extrato líquido (1: 1), 3 vezes ao dia; 0,5 a $2,0 \mathrm{~mL}$ da tintura (1: 10), 3 vezes ao dia; 50 a $100 \mathrm{mg}$ do extrato seco, 2 a 3 vezes ao dia, ou; $150 \mathrm{~mL}$ do infuso (1 a $2 \mathrm{~g}$ da droga) preparado sem abafar, 10 a 15 minutos após o preparo, 2 vezes ao dia; dose diária de 2 a $5 \mathrm{mg}$ de alcaloides totais expressos em boldina $(16,17,20$ 22,52).

\section{7) Pinus pinaster Aiton:}

Família: Pinaceae.

Nome popular: Pinheiro.

Observações: algumas das informações apresentadas não foram comprovadas (52).

Indicações terapêuticas: varizes, distúrbios do fluxo microcirculatório cerebral e cardíaco, fragilidade capilar e prevenção. Indicado como um forte antioxidante, para alterações da função visual, como anti-aging e tratamento de melasma.

Contraindicações: gestantes, lactantes e menores de 6 anos de idade, hipersensibilidade aos componentes.

Efeitos adversos: pode causar transtornos digestivos.

Interações medicamentosas: nenhuma informação encontrada nas referências consultadas.

Posologia: uso oral: 50 a $150 \mathrm{mg}$ do extrato seco ao dia $(20,53,54)$.

18) Rheum officinale Baill.

Família: Polygonaceae.

Nome popular: Ruibarbo.

Indicações terapêuticas: como laxativo na constipação ocasional.

Contraindicações: gravidez, lactação e menores de 10 anos; obstrução intestinal e estenose, atonia, desidratação, constipação crônica, doenças intestinais inflamatórias, hemorroidas, artrite, nefrite e qualquer desconforto gastrointestinal não diagnosticado (contraindicações semelhantes àquelas apresentadas por Senna alexandrina).

Efeitos adversos: cólicas, espasmos e dores abdominais. O uso crônico e abusivo pode levar à hepatite, distúrbios eletrolíticos, acidose metabólica e má absorção de nutrientes (efeitos semelhantes àqueles apresentados por Senna alexandrina).

Interações medicamentosas: potencialização dos efeitos de glicosídeos cardiotônicos e drogas antiarrítmicas como a quinidina (interações semelhantes àquelas apresentadas por Senna alexandrina). Exacerbação dos efeitos de diuréticos tiazídicos, adrenocorticosteroides e raiz de alcaçuz. Redução da absorção de fármacos em geral, devido aumento do trânsito gastrointestinal.

Posologia: uso oral; 10 a $30 \mathrm{mg}$ de derivados hidroxantracênicos, calculados como reína, ingeridos à noite por no máximo duas semanas $(20,22,27,55)$.

19) Rheum palmatum L. ver Rheum officinale Baill.

\section{0) Senna alexandrina Mill.}

Família: Fabaceae.

Nome popular: Sene, sena.

Indicações terapêuticas: como laxativo no tratamento de constipação intestinal ocasional (se o uso de laxativos é necessário todo dia, a causa da constipação deve ser investigada).

Contraindicações: uso prolongado, hipersensibilidade e alergia aos componentes da planta/fitoterápico, gravidez, lactação e para menores de 12 anos. Contraindicado em casos de obstrução intestinal e estenose, atonia, constipação intestinal crônica, distúrbios intestinais não diagnosticados, dores abdominais, desidratação severa, hipocalemia, depleção eletrolítica, doença inflamatória pélvica, período menstrual, cistite, insuficiência hepática, renal ou cardíaca.

Efeitos adversos: dor, cólica e espasmo abdominal (principalmente em pacientes com cólon irritável), diarreia, náuseas e fraqueza. Uso de dosagens elevadas pode causar diarreia com exces- 
siva perda de potássio, albuminúria e hematuria. Uso prolongado pode ocasionar pseudomelanosis coli, nefrite e anormalidades eletrolíticas como hipocalemia, o que pode levar à disfunção cardíaca e neuromuscular (fraqueza muscular), lentidão e inibição do peristaltismo intestinal (atonia colônica e agravamento da constipação), má absorção de nutrientes/medicamentos e concentrações reduzidas de globulinas séricas. As antraquinonas (presentes no Sene) causam alteração na cor da urina, o que pode interferir em exames/testes diagnósti$\cos$.

Interações medicamentosas: redução da absorção de fármacos orais como estrogenios e anticoncepcionais; a hipocalemia (causada pelo uso abusivo) pode potencializar o efeito de glicosídeos cardiotônicos e interagir com antiarrítmicos e fármacos que induzem a reversão do ritmo sinusal (ex. quinidina); diuréticos tiazídicos, adrenocorticosteroides e raiz de alcaçuz podem exacerbar o desequilíbrio eletrolítico e hipocalemia.

Posologia: uso oral; 1 a $2 \mathrm{~g}$ de folhas ou frutos (ou 0,6 a 2,0 $\mathrm{g}$ de frutos e $0,5 \mathrm{a} 2,0 \mathrm{~g}$ de folíolos) ao dia; 0,5 a 2,0 $\mathrm{mL}$ de extrato líquido ao dia ou; $150 \mathrm{mg}$ de extrato seco, de 1 a 3 vezes ao dia; dose diária de 10 a $30 \mathrm{mg}$ (ou $15 \mathrm{a} 30 \mathrm{mg}$ ) de derivados hidroxiantracênicos expressos em senosídeo B. Administrar, preferencialmente, à noite. Não utilizar por mais de uma semana seguida; o uso por mais de 2 semanas requer supervisão médica. As folhas são mais catárticas que os frutos $(16,20-22,27,56,57)$.

\section{1) Valeriana officinalis $L$.}

Família: Caprifoliaceae.

Nome popular: Valeriana.

Indicações terapêuticas: sedativo moderado, hipnótico, distúrbios do sono associados à ansiedade, distúrbios de ansiedade.

Contraindicações: hipersensibilidade e alergia aos componentes da planta, gravidez e lactação (pela falta de dados) e pacientes menores de 12 anos. Não é recomendado ingerir preparações com Valeriana imediatamente (até 2 horas) antes de dirigir ou operar máquinas.

Efeitos adversos: tontura, desconforto gastrointestinal, alergia de contato, cefaleia e midría- se. Uso prolongado pode causar cefaleia, cansaço, insônia, midríase, hepatotoxicidade e desordens cardíacas.

Interações medicamentosas: potencialização do efeito de outros depressores do SNC e barbitúricos e, do efeito sedativo do etanol. Efeito aditivo aos dos anestésicos ou benzodiazepínicos e outros fármacos depressores do SNC. Interações clínicas relevantes com fármacos metabolizados pelas enzimas CIP 2D6 e CIP 3A4/5.

Posologia: uso oral; como sedativo leve, 1 a 3 doses ao dia e, para distúrbios do sono, dose única antes de dormir; não exceder 4 doses diárias (doses para adultos): 144 a $288 \mathrm{mg}$ do extrato seco. Dose diária de 1 a 7,5 mg de ácidos sesquiterpênicos expressos em ácido valerênico. Procurar um médico se os sintomas persistirem por mais de 2 semanas após o tratamento com valeriana $(16,20-22,27,58)$.

\section{CONCLUSÃO}

A comercialização de fitoterápicos ainda é pequena quando comparada aos medicamentos convencionais, concentrando-se, a maioria, em poucas espécies vegetais, o que facilita a instrumentalização dos farmacêuticos para melhor orientar as dispensações e prescrições dos produtos fitoterápicos nas farmácias e drogarias.

As referências contendo informações terapêuticas dos fitoterápicos são escassas para algumas espécies, dificultando a busca por informações confiáveis e de cunho científico. Além disso, muitas espécies vegetais apresentam importantes efeitos adversos, contraindicações e interações, e que, se usadas inadequadamente, podem agravar o quadro de saúde dos usuários. Assim, é de suma importância que o farmacêutico busque conhecimento técnico-científico para orientar os usuários quanto ao uso correto e adequado destes medicamentos.

Diante do exposto, o levantamento das informações sobre os produtos fitoterápicos mais comercializados poderá ser muito útil e servir de apoio aos farmacêuticos, como um instrumento de auxílio para uma melhor orientação e dispensação de fitoterápicos. 
1. BRASIL. Agência Nacional de Vigilância Sanitária. Resolução de Diretoria Colegiada (RDC) $n^{\circ} 26$, de 13 de maio de 2014. Dispõe sobre o registro de medicamentos fitoterápicos e o registro e a notificação de produtos tradicionais fitoterápicos. Diário Oficial da União, $\mathrm{n}^{\circ} 90$, de 14 de maio 2014. Seção 1, p. 52-58. http://pesquisa. in.gov.br/imprensa/jsp/visualiza/index.jsp?jornal=1\&pagina $=52 \&$ data $=14 / 05 / 2014$

2. Bezerra PRP, Meireles DRP, Fernandes HMB, Oliveira Filho AA. Análise farmacoepidemiológica dos medicamentos fitoterápicos dispensados em uma farmácia comunitária no sertão paraibano. Rev Interdiscipl Saúde. 2015;2(2):177-195. http://interdisciplinaremsaude.com. br/Volume_4/Trabalho_01.pdf

3. Botsaris A. Mercado fitoterápico ainda é visto com controvérsia. Disponível em: <http://www.vyaestelar.com. br/post/6756/cresce-interesse-pela-fitoterapia $>$. Acesso em: nov. 2017.

4. Vieira SCH, Sólon S, Vieira MC, Zárate NAH. Levantamento de fitoterápicos manipulados em farmácias magistrais de Dourados-MS. Rev Bras. Farmacogn. 2010;20(1):28-34. DOI: 10.1590/S0102695X2010000100007

5. Carvalho JI, Rocha MS. Interações medicamentosas dos fitoterápicos Ginkgo biloba, Panax ginseng e Hypericum perforatum com medicamentos alopáticos. Rev Acad OswaldoCruz.2016;(10):on-line.http://revista.oswaldocruz. br/Content/pdf/Edicao_10_Carvalho_Jose_Ivam.pdf

6. Heckler APM, Dall'agnol RSA, Heineck I, Rates SMK. Estudo exploratório sobre a dispensação de fitoterápicos e plantas medicinais em Porto Alegre/RS. Acta Farm Bonaer. 2005;24(2):277-283.

7. BRASIL. Ministério da Saúde. Secretaria de Políticas de Saúde. Portaria no 3.916 de 30 de outubro de 1998. Aprova a Política Nacional de Medicamentos. Diário Oficial da União, no 215-E, 10 de nov. 1998. Seção 1, p. 18-22. http:// pesquisa.in.gov.br/imprensa/jsp/visualiza/index.jsp?data $=10 / 11 / 1998$ \&jornal $=1$ \&pagina $=18 \&$ totalArquivos $=226$

8. BRASIL. Casa Civil. Lei No 5.991, de 17 de dezembro de 1973. Dispõe sobre o Controle Sanitário do Comércio de Drogas, Medicamentos, Insumos Farmacêuticos e Correlatos, e dá outras providências. Diário Oficial da União, 19 de dez. 1973. Seção 1, p.13049. Retificado em 21 dez. 1973, Seção 1, p. 13182. https://www.planalto.gov.br/ ccivil_03/leis/15991.htm

9. CFF. Conselho Federal de Farmácia. Resolução da Diretoria Colegiada (RDC) n $\mathrm{n}^{\circ} 585$, de 29 de agosto de 2013. Regulamenta as atribuições clínicas do farmacêutico e dá outras providências. Diário Oficial da União, $\mathrm{n}^{\circ} 186$, 25 set. 2013. Seção 1, p.186-188. http://pesquisa.in.gov. br/imprensa/jsp/visualiza/index.jsp?jornal=1\&pagina $=186 \&$ data $=25 / 09 / 2013$
10. Oliveira LP. Medicamentos fitoterápicos: ênfase na visão dos farmacêuticos alocados em drogarias privadas do município de Colider/MT. FACIDER Rev Cient. 2015;8:1-15.

11. Melo MF, Paiva JA, Correa RM, Normando VMF. Principais plantas medicinais dispensadas em uma farmácia de manipulação. FACEMA. 2018; 4(4):1283-1288.

12. BRASIL. Ministério da Saúde. ANVISA - Agência Nacional de Vigilância Sanitária. Consulta de Medicamentos. Disponível em: https://consultas.anvisa.gov.br/\#/ medicamentos/. Acesso em: out. 2017.

13. CFF. Conselho Federal de Farmácia. Resolução da Diretoria Colegiada (RDC) $\mathrm{n}^{\circ} 586$, de 29 de agosto de 2013. Regula a prescrição farmacêutica e dá outras providências. Diário Oficial da União, nº 187, 26 set. 2013. Seção 1, p.136-138. http://pesquisa.in.gov.br/impren$\mathrm{sa} / \mathrm{jsp} /$ visualiza/index.jsp?jornal=1\&pagina $=136 \&$ data $=26 / 09 / 2013$

14. Rang HP, Ritter JM, Flower RJ, Henderson G. Rang \& Dale: farmacologia. $8^{\mathrm{a}}$ ed. Rio de Janeiro: Elsevier. 2016.

15. Bello CM, Montanha JA, Schenkel EP. Análise das bulas de medicamentos fitoterápicos comercializados em Porto Alegre, RS, Brasil. Rev Bras Farmacogn. 2002, 12(2):7583. DOI: 10.1590/S0102-695X2002000200004.

16. BRASIL. Agência Nacional de Vigilância Sanitária. Memento Fitoterápico da Farmacopeia Brasileira. $1^{a}$ ed. Brasília: Anvisa. 2016. http://portal.anvisa.gov.br/documents/33832/2909630/Memento+Fitoterapico/a80ec477-bb36-4ae0-b1d2-e2461217e06b

17. BRASIL. Agência Nacional de Vigilância Sanitária. Formulário de Fitoterápicos da Farmacopeia Brasileira. 1 ${ }^{\mathrm{a}}$ ed. Brasília: Anvisa. 2011. http://portal.anvisa.gov.br/ documents/33832/259456/Formulario_de_Fitoterapicos_da_Farmacopeia_Brasileira.pdf/c76283e-b-29f6-4b$15-\overline{8} 75 \overline{5}-2073 \mathrm{e} 5 \mathrm{~b} 4 \mathrm{c} 5 \mathrm{bf}$

18. Marliére LDP, Ribeiro $\mathrm{AQ}$, Brandão MGL, Klein $\mathrm{CH}$, Acurcio FA. Utilização de fitoterápicos por idosos: resultados de um inquérito domiciliar em Belo Horizonte (MG), Brasil. Rev Bras Farmacogn. 2008;18(0):754-760. DOI: 10.1590/S0102-695X2008000500021.

19. Moraes MB, Marques MS, Soares ECS, Damascena RS. Perfil da Prescrição de Fitoterápicos em uma Farmácia de Manipulação de Vitória da Conquista-BA entre 2014 a 2018. Id on Line Rev. Mult. Psic. 2019; 13(43):76-86.

20. TROPICOS. Disponível em: $<$ http://www.tropicos.org/ NameSearch.aspx> Acesso em: out. 2017.

21. BRASIL. Agência Nacional de Vigilância Sanitária. Instrução Normativa (IN) nº 02 de 13 de maio de 2014. Publica a "Lista de medicamentos fitoterápicos de registro simplificado" e a "Lista de produtos tradicionais fitoterápicos de registro simplificado". Diário Oficial da União, 
$\mathrm{n}^{\circ}$ 90, 14 de maio de 2014. Seção 1, p.58-61. http:// pesquisa.in.gov.br/imprensa/jsp/visualiza/index.jsp?jornal $=1 \&$ pagina $=58 \&$ data $=14 / 05 / 2014$

22. Barnes J, Anderson LA, Philipson JD. Fitoterápicos. $3^{\text {a }}$ ed. Porto Alegre: Artmed. 2012.

23. EMA. European Medicines Agency. Committee on Herbal Medicinal Products (HMPC). Final Community Herbal Monograph on Aesculus hippocastanum L., Semen. Londres, 16 de julho de 2009. https://www.ema.europa. $\mathrm{eu} / \mathrm{en} /$ documents/herbal-monograph/final-community-herbal-monograph-aesculus-hippocastanum-1-semen en.pdf

24. WHO. World Health Organization. Monographs on selected medicinal plants - volume 2. World Health Organization: Geneva, Switzerland. 2002. https://apps.who. int/medicinedocs/en/d/Js4927e/

25. MEDSCAPE. Medscape: drugs e diseases. Disponível em: $<$ https://reference.medscape.com $>$. Acesso em: out. 2017.

26. EMA. European Medicines Agency. Committee on Herbal Medicinal Products (HMPC). Final Community Herbal Monograph on Aloe barbadensis Mill. and on Aloe (various species, mainly Aloe ferox Mill. and its Hybrids), Folii Succus Siccatus. Londres, 22 de novembro de 2016. https://www.ema.europa.eu/en/documents/ herbal-monograph/final-european-union-herbal-monograph-aloe-barbadensis-mill-aloe-various-species-mainly-aloe-ferox_en.pdf

27. WHO. World Health Organization. Monographs on selected medicinal plants - volume 1. World Health Organization: Geneva, Switzerland. 1999. https://apps.who. int/medicinedocs/en/d/Js2200e/

28. EMA. European Medicines Agency. Committee on Herbal Medicinal Products (HMPC). Foeniculum vulgare Miller Subsp. vulgare Var. dulce (Miller) Thellung, Fructus: Fennel Fruit, Sweet. Londres: EMA. 2010. https:// www.ema.europa.eu/en/documents/herbal-summary/ foeniculum-vulgare-miller-subsp-vulgare-var-dulce-miller-thellung-fructus-fennel-fruit-sweet-hmpc_en.pdf

29. EMA. European Medicines Agency. Committee on Herbal Medicinal Products (HMPC). Final Community Herbal Monograph on Foeniculum vulgare Miller Subsp. vulgare VAR. vulgare, Aetheroleum. Londres, 05 de julho de 2007. https://www.ema.europa.eu/en/documents/ herbal-monograph/final-community-herbal-monograph-foeniculum-vulgare-miller-subsp-vulgare-var-vulgare-aetheroleum_en.pdf

30. EMA. European Medicines Agency. Committee on Herbal Medicinal Products (HMPC). Final Community Herbal Monograph on Foeniculum vulgare Miller Subsp. vulgare var. vulgare, Fructus. Londres, 06 de agosto de 2007. https://www.ema.europa.eu/en/documents/herbal-monograph/final-community-herbal-monograph-foeniculum-vulgare-miller-subsp-vulgare-var-vulgare-fructus_en.pdf
31. Mozaffarpur AS, Naseri M, Esmaeilidooki MR, Kamalinejad M, Bijani A. The effect of Cassia fistula emulsion on pediatric functional constipation in comparison with mineral oil: a randomized, clinical trial. DARU J Pharm Sci. 2012;20(1):83. DOI: 10.1186/2008-2231-20-83.

32. Panda SK, Padhi LP, Mohanty G. Antibacterial activities and phytochemical analysis of Cassia fistula (Linn.) leaf. J Adv Pharm Technol. Res. 2011;2(1):62-67. DOI: 10.4103/2231-4040.79814.

33. Viegas Junior C, Rezende A, Silva DHS, Castro-Gambôa I, Bolzani VS, Barreiro EJ, Miranda ALP, Alexandre-Moreira MS, Young MCM. Aspectos químicos, biológicos e etnofarmacológicos do gênero Cassia. Quím Nova. 2006;29(6):1279-1286.

34. Phongpaichit S, Pujenjob N, Rukachaisirikul V, Ongsakul M. Antifungal activity from leaf extracts of Cassia alata L., Cassia fistula L. and Cassia tora L. Songklanakarin J Sci Technol. 2004;26(5):741-748.

35. EMA. European Medicines Agency. Committee on herbal Medicinal Products (HMPC). Final Community Herbal Monograph on Cichorium intybus L., Radix. Londres, 15 de janeiro de 2013. https://www.ema.europa.eu/ en/documents/herbal-monograph/final-community-herbal-monograph-cichorium-intybus-1-radix_en.pdf

36. Nandagopal S, Kumari BDR. Phytochemical and antibacterial studies of chicory (Cichorium intybus L.) - a multipurpose medicinal plant. Advan Biol Res. 2007;1(12):17-21.

37. Petrovic J, Stanojkovic A, Comic LJ, Curcic S. Antibacterial activity of Cichorium intybus. Fitoterapia. 2004;75(78):737-739. DOI: 10.1016/j.fitote.2004.05.001

38. EMA. European Medicines Agency. Committee on Herbal Medicinal Products (HMPC). Final Community Herbal Monograph on Crataegus spp., Folium Cum Flore. Londres, 05 de abril de 2016. https:/www.ema.europa.eu/en/ documents/herbal-monograph/final-european-union-herbal-monograph-crataegus-spp-folium-cum-flore_en.pdf

39. EMA. European Medicines Agency. Committee on Herbal Medicinal Products (HMPC). Community Herbal Monograph on Cynara scolymus L., Folium. Londres, 13 de setembro de 2011. https://www.ema.europa.eu/en/ documents/herbal-monograph/superseded-community-herbal-monograph-cynara-scolymus-1-folium_en.pdf

40. WHO. World Health Organization. Monographs on selected medicinal plants - volume 4. Geneva, Switzerland: World Health Organization. 2009. http:// apps.who.int/medicinedocs/en/m/abstract/Js $16713 \mathrm{e} /$ 41. EMA. European Medicines Agency. Committee on Herbal Medicinal Products (HMPC). Final Community Herbal Monograph on Rhamnus purshianus D.C., Cortex. Londres, 07 de setembro de 2007. https:/www. ema.europa.eu/en/documents/herbal-monograph/final-community-herbal-monograph-rhamnus-purshianus-dc-cortex_en.pdf 
42. EMA. European Medicines Agency. Committee on Herbal Medicinal Products (HMPC). Final Community Herbal Monograph on Gentiana lutea L., Radix. Londres, 12 de novembro de 2009. https://www.ema.europa.eu/ en/documents/herbal-monograph/superseded-community-herbal-monograph-gentiana-lutea-l-radix-first-version_en.pdf

43. WHO. World Health Organization. Monographs on Selected Medicinal Plants - Volume 3. Geneva, Switzerland: World Health Organization. 2007. https://apps.who. int/medicinedocs/en/m/abstract/Js14213e/

44. EMA. European Medicines Agency. Committee on Herbal Medicinal Products (HMPC). Final Community Herbal Monograph on Ginkgo biloba L., Folium. Londres, 28 de janeiro de 2015. https:/www.ema.europa.eu/en/ documents/herbal-monograph/final-european-union-herbal-monograph-ginkgo-biloba-1-folium_en.pdf

45. EMA. European Medicines Agency. Committee on Herbal Medicinal Products (HMPC). Community Herbal Monograph on Hedera helix L., Folium. Londres, 24 de novembro de 2015. https://www.ema.europa.eu/en/documents/herbal-monograph/superseded-european-union-herbal-monograph-hedera-helix-1-folium-revision-1_ en.pdf

46. Kiertsman B \& Zuquim SL. O extrato seco de Hedera helix no tratamento das infecções de vias aéreas na infância. Pediatr Mod. 2008;44(4):143-149.

47. EMA. European Medicines Agency. Committee on Herbal Medicinal Products (HMPC). Final European Union herbal monograph on Matricaria recutita L., flos. Londres, 07 de julho de 2015. https://www.ema.europa.eu/ en/documents/herbal-monograph/final-european-union-herbal-monograph-matricaria-recutita-1-flos_en.pdf

48. EMA. European Medicines Agency. Committee on Herbal Medicinal Products (HMPC). Final European Union herbal monograph on Matricaria recutita L., aetheroleum. Londres, 07 de julho de 2015. https://www.ema. europa.eu/en/documents/herbal-monograph/final-european-union-herbal-monograph-matricaria-recutita-1-aetheroleum_en.pdf

49. BRASIL. Ministério da Saúde e ANVISA (org.). Monografia da espécie Mikania glomerata (Guaco). Fonte do Recurso: Ação 20K5 (DAF/SCTIE/MS)/2012. Brasília, 2014. Disponível em: <http://portalarquivos2.saude.gov. br/images/pdf/2016/fevereiro/05/Monografia-Mikania. pdf $>$. Acesso em: nov. 2017.

50. Elixir Paregórico. Responsável técnico Carlos E. de Carvalho. Joinville: Laboratório Catarinense, 2015. Bula de remédio. http://www.catarinensepharma.com.br/upload/ produto/BULA_ELIXIR_PAREG RICO_PACIEN-

\section{TE_56c313eca636e.pdf}

51. EMA. European Medicines Agency. Committee on Herbal Medicinal Products (HMPC). Final Community Herbal Monograph on Passiflora incarnata L., Herba. Londres, 25 de março de 2014. https://www.ema.europa.eu/ en/documents/herbal-monograph/final-community-herbal-monograph-passiflora-incarnata-1-herba_en.pdf

52. EMA. European Medicines Agency. Committee on Herbal Medicinal Products (HMPC). Final European Union herbal monograph on Peumus boldus Molina, folium. Londres, 22 de novembro de 2016. https://www.ema. europa.eu/en/documents/herbal-monograph/final-european-union-herbal-monograph-peumus-boldus-molina-folium_en.pdf

53. Flebon: comprimidos. Responsável técnico Dra. Marcia Weiss I. Campos. Rio de Janeiro: Farmoquimica, 2011. Bula de remédio. http://www.anvisa.gov.br/datavisa/fila_bula/frmVisualizarBula.asp?pNuTransa$\mathrm{cao}=6450122018 \&$ pIdAnexo $=10657673$

54. Iravani S, Zolfaghari B. Pharmaceutical and nutraceutical effects of Pinus pinaster bark extract. Res Pharm Sci. 2011;6(1):1-11.

55. EMA. European Medicines Agency. Committee on Herbal Medicinal Products (HMPC). Final Community Herbal Monograph on Rheum palmatum L. and Rheum officinale Baillon, Radix. Londres, 31 de outubro de 2007. https://www.ema.europa.eu/en/documents/herbal-monograph/final-community-herbal-monograph-rheum-palmatum-1-rheum-officinale-baillon-radix_en.pdf

56. EMA. European Medicines Agency. Committee on Herbal Medicinal Products (HMPC). Final Community Herbal Monograph on Cassia senna L. and Cassia angustifolia Vahl, Folium. Londres, 26 de outubro de 2006. https:// www.ema.europa.eu/en/documents/herbal-monograph/ final-community-herbal-monograph-cassia-senna-1-cassia-angustifolia-vahl-folium_en.pdf

57. EMA. European Medicines Agency. Committee on Herbal Medicinal Products (HMPC). Final Community Herbal Monograph on Cassia senna L., Fructus and Cassia angustifolia Vahl, Fructus. Londres, 26 de outubro de 2006. https://www.ema.europa.eu/en/documents/herbal-monograph/final-community-herbal-monograph-cassia-senna-l-fructus-cassia-angustifolia-vahl-fructus_en.pdf

58. EMA. European Medicines Agency. Committee on Herbal Medicinal Products (HMPC). Final European Union herbal monograph on Valeriana officinalis L., radix. Londres, 02 de fevereiro de 2016. https://www. ema.europa.eu/en/documents/herbal-monograph/final-european-union-herbal-monograph-valeriana-officinalis-1-radix_en. 